\title{
Mathematical methods in studying the territorial oligopolistic market of freight transportation
}

\author{
V.A. Bogachev ${ }^{1}$, A.S. Kravets ${ }^{1,}$, and T.V. Bogachev ${ }^{2}$ \\ ${ }^{1}$ Rostov State Transport University (RSTU), 2, Rostovskogo Strelkovogo Polka Narodnogo \\ Opolcheniya sq., Rostov-on-Don, 344038, Russia \\ ${ }^{2}$ Rostov State University of Economics (RSUE), 69, Bolshaya Sadovaya str., Rostov-on-Don, \\ 344002, Russia
}

\begin{abstract}
A multi-agent approach has been developed to find the optimal distribution of freight traffic on the considered railway loop for multimodal transportation carried out within the framework of an oligopolistic market. At the first stage of research, the method of economic-geographical delimitation of the «influence areas» of loading stations, developed earlier by the authors, is applied. The obtained territorial picture of the rational distribution of traffic flows is used further when introducing restrictions in a multi-criteria optimization problem, which is solved as an integer programming problem in the environment of the system of analytical calculations. As a result, on the basis of an assessment of the transport and technological infrastructure of the loop and the cost of transport services, a mathematical model is built that allows to optimize the process of freight transportation.
\end{abstract}

\section{Introduction}

\subsection{Literature review}

The issues of studying the efficiency of multimodal cargo transportation, including transshipment in seaports, have been the subject of many recent studies (see, for example, [1-10]). The globalization of transport processes, accompanied by pervasive digitalization, as well as differences in the goals and objectives of the participants in these processes, lead to the need for a deeper and more comprehensive study of them. Below is a brief analysis of a number of works related to the study of these processes taking place in regional transport systems.

In [1] a number of different schemes for the transportation of goods are considered. The choice of the optimal cost scheme is proposed to be determined using a logistic approach based on the cybernetic "white box" model, taking into account the input parameters necessary for the shipper. When developing new methods of operation of production systems, including transport systems, special attention is paid to the possibility of using digital technologies. In [2], the main trends in intelligent logistics are presented, including with the

\footnotetext{
* Corresponding author: kravec_as@mail.ru
} 
use of Digital Twin. In [3], to reduce the cost of transportation, it is proposed to solve the transport problem using the simplex method. In this case, the parameters of supply and demand are stochastic, and the cost of transportation is variable. The aim of the work is to minimize transport costs, which satisfy a number of requirements depending on the size of the transported goods. In [4], a mathematical model for the delivery of bulk cargo was developed on the basis of a systematic approach and principles of logistics, taking into account the interaction of manufacturers, transport companies and consumers. The model allows solving a wide range of problems facing both manufacturers (for example, when planning the supply chain on their own) and before the carrier, related to planning and managing the operation of transport infrastructure elements. The model takes into account the variability of the technical parameters of the rolling stock, loading and unloading mechanisms, time and quantity parameters of freight traffic.

The difference in the interests of transport participants is noted in [5]. Differences in their goals and objectives determine the difficulties in developing a unified transport strategy and necessitates a deeper study of transport technologies in order to find new methods that will allow finding a result that is beneficial for all participants at the same time.

In [6], a general approach was developed in the study of the oligopolistic market of cargo transportation, in which an economic-geographical model is built for the transport area under consideration, which makes it possible to identify the «influence areas» of loading stations. The resulting territorial picture of the delimitation of cargo flows in the region makes it possible to formulate recommendations when choosing rational distributions of these flows to the unloading stations. In [7], an approach is presented in the study of distributions of freight traffic based on two-criteria optimization with time parameters, in which the peculiarities of the warehouse and transport infrastructure of the region under consideration are taken into account in sufficient detail.

In [8], a mathematical model of the distribution of export cargo flows is proposed, built on the basis of game theory and graph theory. As a result of the simulation, it becomes possible to attract additional cargo volumes by optimizing the cost of transportation on a specific route. In [9], an approach based on the principle of entropy maximization is presented, which allows combining various data to develop a model of the logical behavior of a cargo for one of the states of Australia. The resulting model is a system of related elements, which includes models for the production of goods and their distribution. The main focus is on commodity flows, the availability of vehicles in the production and consumption zones and the effective interaction of various modes of transport in the logistics chains for the transportation of goods. In [10], a model based on the forecast of traffic flows, taking into account infrastructural constraints, is presented, which makes it possible to minimize the difficulties in traffic.

\subsection{The relevance of the development of new approaches in the study of multimodal transportation of grain cargo}

The above analysis of the works allows us to conclude about the relevance of studies aimed at finding rational schemes for multimodal transportation of goods and carried out on the basis of synergetic approaches, in which the synthesis of previously used ideas is carried out.

This paper develops an approach to the study of the efficiency of the freight transport process, which combines two methods of different mathematical nature, mentioned in the above review. The first method [6], based on the principles of analytical geometry, allows you to build an economic-geographic model of the oligopolistic territorial transportation market for the considered transport loop. The application of the second method [7] consists in solving a multicriteria transport problem posed for the considered transport and 
technological system in the form of an integer programming problem. In both cases, the practical implementation of the developed algorithms is carried out in the environment of the system of analytical calculations.

We will consider the strategically important raw materials exported from Russia - grain, as the transported cargo. The mass character of grain cargoes and relatively low cost in many respects contribute to the integrated use of rail and sea transport during their transportation. Note that the research methodology developed in the article is very general and is applicable to the transportation of other types of cargo.

Table 1. Characteristics of the investigated traffic flow.

\begin{tabular}{|c|c|c|c|c|c|c|c|c|c|c|c|c|c|}
\hline \multirow{3}{*}{$\begin{array}{l}\text { Loadi } \\
\text { ng } \\
\text { station } \\
\text { s }\end{array}$} & \multirow{3}{*}{$\begin{array}{l}\text { Numb } \\
\text { er } \\
\text { forwa } \\
\text { rder } \\
\text { routes }\end{array}$} & \multicolumn{12}{|c|}{ Unloading stations } \\
\hline & & \multicolumn{3}{|c|}{ Novorossijsk } & \multicolumn{3}{|c|}{ Tuapse } & \multicolumn{3}{|c|}{ Taman' } & \multicolumn{3}{|c|}{ Azov } \\
\hline & & $l_{i j}$ & $t_{i j}$ & $c_{i j}$ & $l_{i j}$ & $t_{i j}$ & $c_{i j}$ & $l_{i j}$ & $t_{i j}$ & $c_{i j}$ & $l_{i j}$ & $t_{i j}$ & $c_{i j}$ \\
\hline Celina & 3 & 460 & 1.43 & 48.9 & 471 & $.46^{1}$ & $8.9^{4}$ & $31^{5}$ & $.65^{1}$ & $2.5^{5}$ & $65^{1}$ & $.51^{0}$ & $0.2^{3}$ \\
\hline $\begin{array}{c}\text { Albas } \\
\text { hi }\end{array}$ & 3 & 251 & 0.78 & $5.3^{3}$ & 301 & $.94^{0}$ & $9.4^{3}$ & $06^{3}$ & $.95^{0}$ & $9.4^{3}$ & $51^{1}$ & $.47^{0}$ & $8.8^{2}$ \\
\hline $\begin{array}{c}\text { Belogl } \\
\text { inskay } \\
\text { a }\end{array}$ & 3 & 341 & 1.06 & $1.4^{4}$ & 352 & $.09^{1}$ & $1.4^{4}$ & $12^{4}$ & $.28^{1}$ & $5.0^{4}$ & $69^{2}$ & $.84^{0}$ & $6.6^{3}$ \\
\hline $\begin{array}{l}\text { Tihore } \\
\text { ckaya }\end{array}$ & 3 & 271 & 0.84 & $6.6^{3}$ & 282 & $.88^{0}$ & $7.9^{3}$ & $42^{3}$ & $.06^{1}$ & $1.4^{4}$ & $99^{1}$ & $.62^{0}$ & $1.4^{3}$ \\
\hline $\begin{array}{c}\text { Izobil' } \\
\text { naya }\end{array}$ & 3 & 373 & 1.16 & $3.2^{4}$ & 384 & $.19^{1}$ & $3.2^{4}$ & $4^{4}$ & $.38^{1}$ & $7.1^{4}$ & $6^{3}$ & $.13^{1}$ & $3.2^{4}$ \\
\hline
\end{tabular}

When choosing schemes for multimodal transportation of goods exported through the seaports of the Azov-Black Sea basin, it is natural to take into account the factors that objectively affect the activity of these ports. Among such factors, it is necessary to highlight, first of all, their geographical position (including relative to the railway transport infrastructure) and technical equipment. At the same time, the increasing level of competition between rail and road transport modes is an external factor that stimulates the finding of optimal freight transport schemes in relation to rail transport, especially if it is involved in multimodal transport. Attention should also be paid to the dispersion of grain loading stations in southern Russia, the ramification of communication lines (including in the direction of ports), as well as the presence of a large number of transport companies on the market. All this creates conditions for the functioning of a full-fledged market of transport services in the specified region. Thus, for consignor, it is a very urgent task that, among the possible schemes of cargo transportation, in accordance with the indicators of the transportation process of interest to them, to have a possibility choose those that turn out to be the most rational.

Competition between the ports of the Azov-Black Sea basin is also facilitated by their universatility in terms of the range of processed cargo. The effect of market mechanisms is revealed, for example, by analyzing the dynamics of the share of these cargoes for each of the ports. Even small shifts in the distribution of cargo flows to one of the ports can entail very significant changes in the transshipment indicators for other ports. Moreover, despite the differences in the capacity of the port infrastructure, tonnage and types of ships accepted, competition in the transportation of grain is manifested even in the sections of various nomenclature groups.

In this work, it is assumed that the grain cargo intended for transportation is located at five loading stations: Celina, Albashi, Beloglinskaya, Tihoreckaya and Izobil'naya. Four port stations are considered as unloading stations: Novorossijsk, Tuapse, Taman' and Azov. Table 
1 shows the characteristics of the transportation process, which will be used further in the study of the corresponding traffic flows.

\section{Preliminary results}

\subsection{Finding the cost indicators of the transportation process}

Let's move on to the first stage of constructing a mathematical model of the oligopolistic freight market in the region. At this stage, which is of a preliminary nature, we begin with the fact that for each of the loading stations considered in this paper we find the expression for the dependence of the cost $c$ (thousand rubles) of transportation of one freight wagon on the length $l(\mathrm{~km})$ of the route traveled. In this case, the initial numerical data are used, which characterize the traffic flow of grain cargo between loading stations and unloading stations, presented above in table 1. Based on the expressions found for the cost of transportation, we further apply the method of economic-geographical differentiation of the «influence areas» of loading stations, developed in [6].

After processing the available numerical data using the least squares method, we find that for each loading station the desired dependence has the form: $c=p+q l$, where $p$ and $q$ are cost indicators that express the costs per carriage of initial and final and movement operations (per $1 \mathrm{~km}$ of route). Found specific expressions of dependence are given in table 2. Note that the linear form of the considered dependence is manifested for various cargoes and ranges of their transportation [6], that is, it has a very stable character.

Table 2. The expressions of transportation cost for loading stations.

\begin{tabular}{|c|c|c|}
\hline № & Loading stations & $c=p+q l$ \\
\hline 1 & Celina & $c=20.08+0.062 l$ \\
\hline 2 & Albashi & $c=18.21+0.070 l$ \\
\hline 3 & Beloglinskaya & $c=20.90+0.059 l$ \\
\hline 4 & Tihoreckaya & $c=17.74+0.070 l$ \\
\hline 5 & Izobil'naya & $c=23.81+0.052 l$ \\
\hline
\end{tabular}

Let us pay attention to the fact that, as in a number of previously considered situations, the difference between loading stations is manifested not only in the cost of initial and final operations, but also in the cost of motion operations. As will be seen from the examples discussed below, the value of the cost of movement operations fundamentally affects the part of the territorial picture of the freight transport market located quite far from the loading stations.

\subsection{Building a territorial model of the freight market by economic-geographical method}

In this section, a geometric Euclidean model (GEM) of the territorial oligopolistic freight market created by the loading stations under consideration will be built. The specified model is built using the method of economic-geographical delineation of «influence areas» of loading stations, which are positioned as participants in an oligopoly. The cost of transporting goods from loading stations to the destination is an indicator according to which the «influence areas» of these stations are delineated. Note that from the point of view of the transport time of the transportation process, the GEM structure is directly related to the travel time. 
Earlier, using examples, it was shown [6] that under the condition of a sufficiently dense network of railways in the region, «idealization» of the transport and logistics situation is permissible. It consists in the fact that Euclidean distances on a flat geographical map between the beginning and end of these routes are taken as the lengths of train routes. The expressions for the cost of transportation obtained in Section 4 (see table 2) allow us to construct a GEM of an oligopolistic grain transportation market created by the loading stations under consideration. The functioning of such a market in its simplest form can be considered, for example, within the framework of any of the operator companies that transport the specified cargo at a given transport range. From an economic point of view, with this approach, loading stations can be positioned as oligopolists who compete with each other for a more rational use of the company's transport resources.

Below is a summary of the theoretical foundations of the method of economicgeographical delineation of the «influence areas» of loading stations for the case of a duopoly.

\subsubsection{Geometric foundations of the method}

Let us first consider the situation when there are only two loading stations on the transportation market, which we will position as duopolists.

Let $L$ be the distance between the locations of the 1 st and 2 nd duopolists, $p_{i}>0$ and $q_{i}>$ 0 the costs of the initial, final and movement operations ( 1 per $\mathrm{km}$ of route) spent by the $i$ duopolist $(i=1,2)$ (per carriage wagon). In order to «tie» the model of the transportation market formed using the economic-geographical method to the territory where the considered transport polygon is located, we will introduce a Cartesian coordinate system on a flat geographical map of this territory. The introduction of this system is conditional and it is required in order to carry out the corresponding constructions on the plane using the method of analytical geometry. Let's assume that the 1 st and 2 nd duopolists are at points $A\left(-\frac{L}{2}, 0\right)$ and $\left(\frac{L}{2}, 0\right)$. Then the equation of the line delimiting the «influence areas» of duopolists can be written in the form:

$$
p_{1}+q_{1} \sqrt{\left(x+\frac{L}{2}\right)^{2}+y^{2}}=p_{2}+q_{2} \sqrt{\left(x-\frac{L}{2}\right)^{2}+y^{2}}
$$

After transforming equation (1) by the analytical computation system, we arrive at an equation (see [6]), from the form of which it follows that we are dealing with an algebraic line on a plane whose order does not exceed 4 . In this case, the order of the line is 4 if and only if $q_{1} \neq q_{2}$. More precisely, the line under consideration is Descartes' oval (in particular, Pascal's limaçon), the foci of which are located at points $A\left(-\frac{L}{2}, 0\right)$ and $B\left(\frac{L}{2}, 0\right)$. Let us illustrate the above constructions with two examples. 


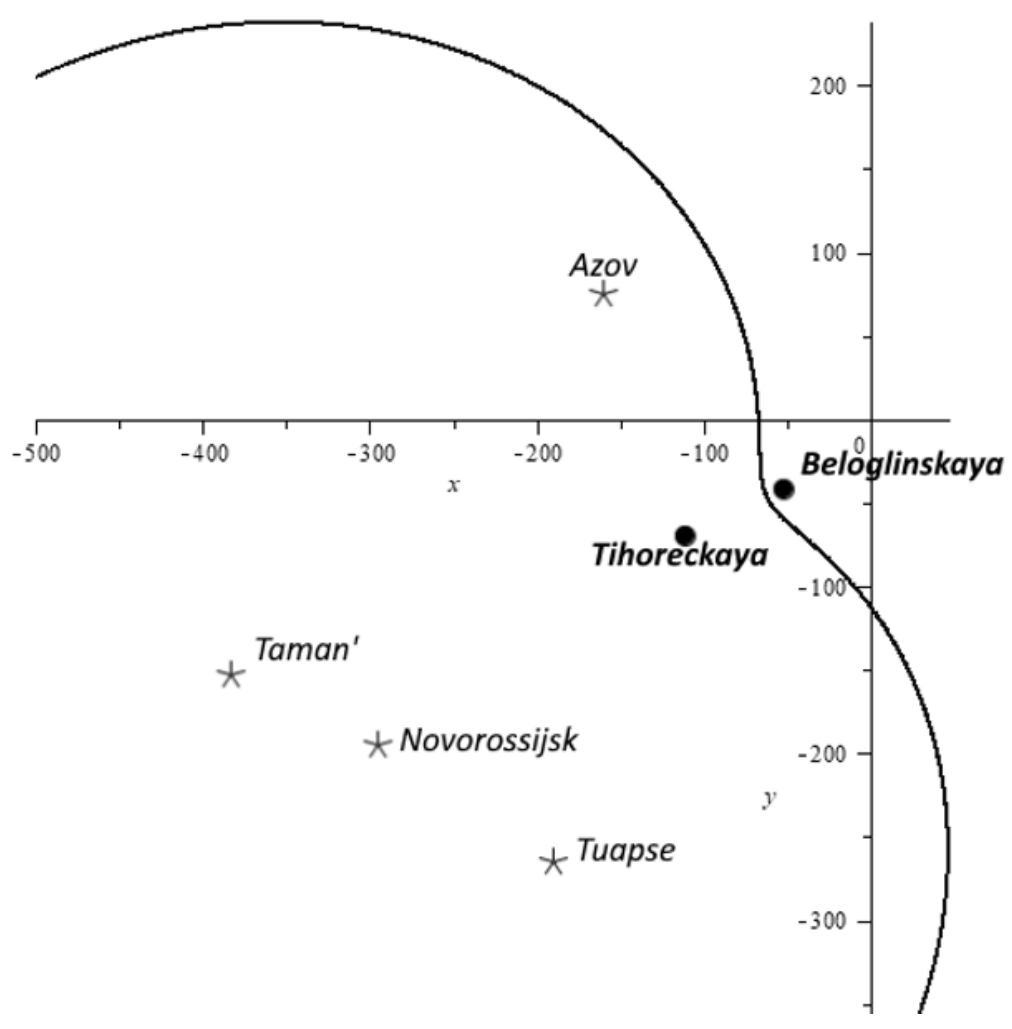

Fig. 1. «Influence areas» of stations Beloglinskaya and Tihoreckaya in a duopolistic situation.

In the first example, we will assume that the loading stations Beloglinskaya and Tihoreckaya are involved in the transportation process. The constructions made by the system of analytical calculations show that the territory under consideration is delimited by a are delimitated line, which is Pascal's limaçon (figure 1). All four port stations, which are considered in this work, fall into the «influence area» of Tihoreckaya station. The indicated «inequality» is explained by the fact that the costs of initial and final operations at Tihoreckaya station are less than similar costs at Beloglinskaya station (see table 2). Note that in this case, Beloglinskaya station turns out to be more competitive with respect to destinations that could be located at sufficiently large distances from both stations (figure 1). This is due to the fact that the cost of movement operations is less than that of Tihoreckaya station (table 2). 


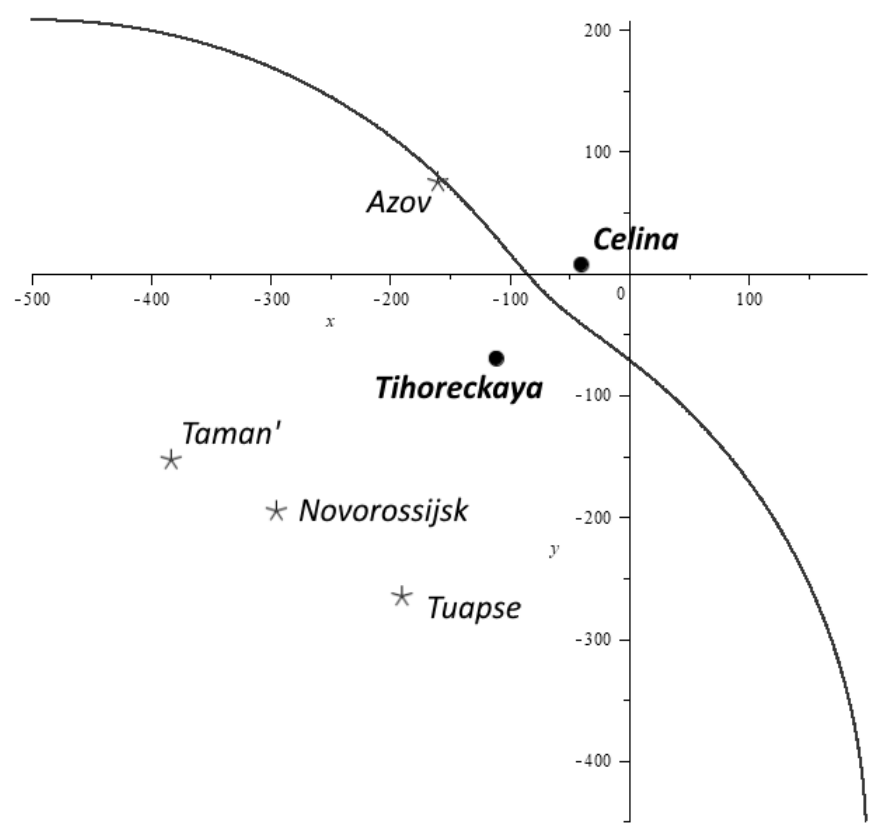

Fig. 2. «Influence areas» of Celina and Tihoreckaya stations in a duopolistic situation.

In the second example, consider a duopoly formed by the Celina and Tihoreckaya loading stations. In general, the territorial picture in relation to the «influence areas» of these stations (figure 2) is similar to that obtained in the first example. However, since the costs of initial and final operations at Celina station are somewhat less than at Beloglinskaya station (see table 2), in the second example the port station Azov is located on the line (which is also Pascal's limaçon), delimiting the «influence areas» of the stations Celina and Tihoreckaya.

Let's move on to considering the joint operation of five loading stations.

\subsubsection{Territorial picture of the oligopolistic freight transport market}

In describing the territorial picture of the freight market, created by five loading stations, generally speaking, $C_{5}^{2}=10$ lines are involved. Each of these lines is the border of the «influence areas» of the two loading stations in the corresponding duopolistic situation. Images of these lines for the stations considered in this work are shown in figure 3. 


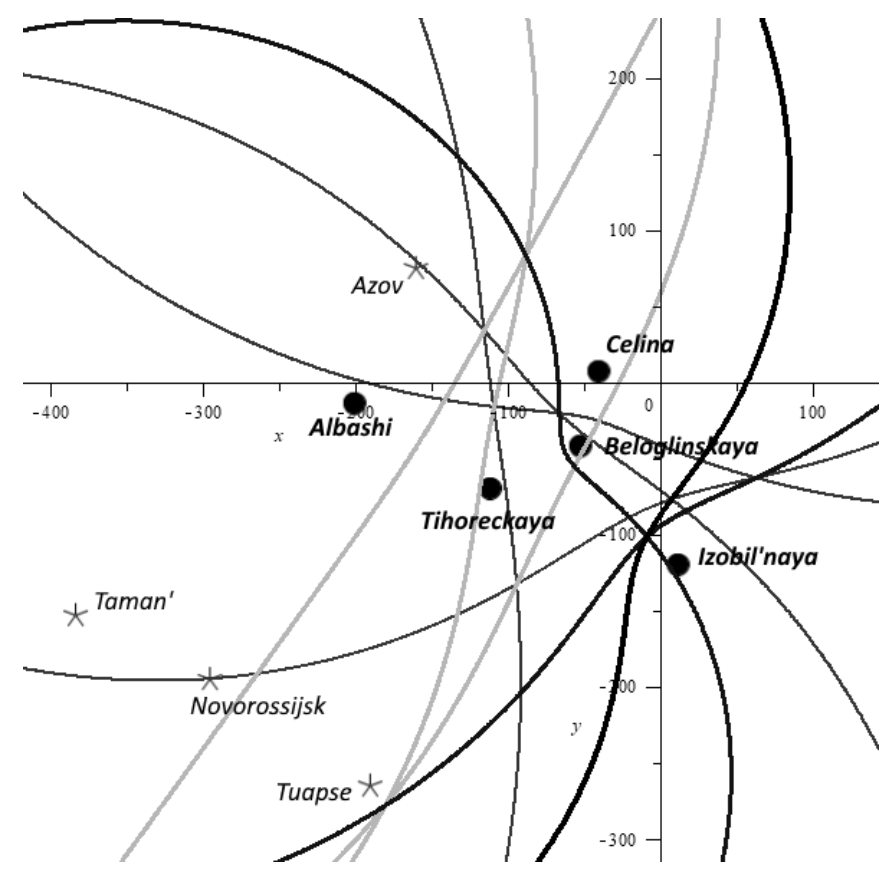

Fig. 3. Images of lines delimiting the «influence areas» of loading stations in duopolistic situations.

Note that the line delimiting the «influence areas» of Albashi and Tihoreckaya stations is a hyperbola branch, which is an algebraic line of the second order. This circumstance is explained by the fact [6] that the costs of movement operations at these two stations coincide (see table 2). At the same time, since the costs of the initial and final operations at Albashi station are somewhat higher than at Tihoreckaya station (table 2), its «influence areas» is somewhat «inferior» to the «influence area» of Tihoreckaya station.

In an oligopolistic situation, the boundary of the «influence areas» of each of the five loading stations is a broken line, generally speaking, of four curvilinear components. Each of these components is part of the Descartes oval, which delimits the «influence area» of a given station with the «influence area» of any one of the other four stations in a duopolistic situation. (Note that these components may turn out to be unconnected sets on the plane.) The territorial picture of the oligopolistic freight market created by the loading stations considered in this work is shown in figure 4.

So, in the «influence area» of the Albashi loading station, there are three port stations: Novorossijsk, Taman' and Azov. Thus, within the GEM, this loading station is dominant. The port station Tuapse falls into the «influence area» of the Tihoreckaya loading station. As already noted, the results obtained are a consequence of the fact that the costs of initial and final operations at Albashi and Tihoreckaya stations are less than similar costs at the other three loading stations. 


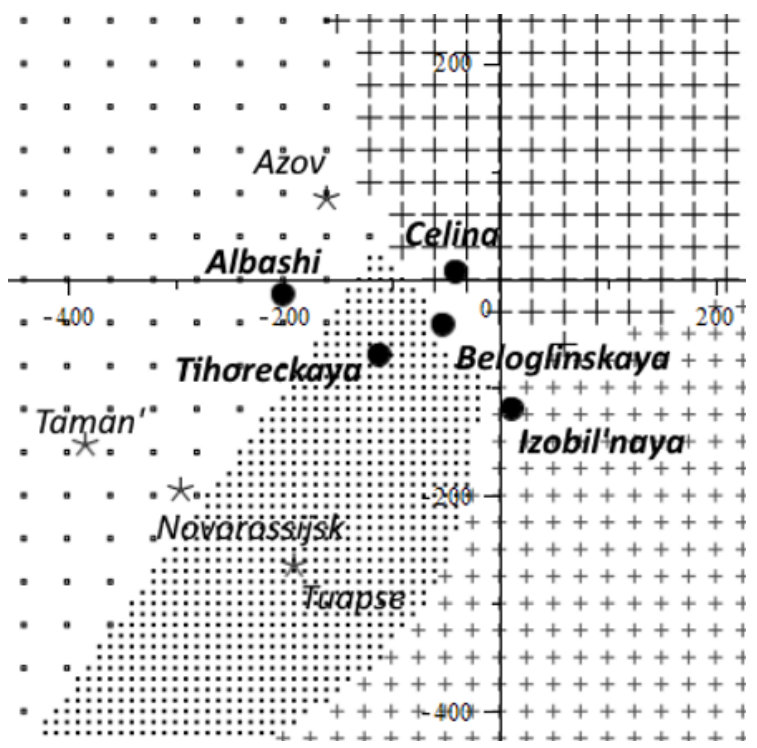

Fig. 4. Territorial picture of the freight transport market in an oligopolistic situation.

Regarding the possible correction of the GEM by means of a geometric routing model (GRM) (for this, see, for example, [6]), we note that in this case such a need does not arise, at least for two reasons. Firstly, the railway network in the considered transport area is quite dense. Secondly, in the present study, the results obtained above are auxiliary.

\section{Results}

\subsection{Mathematical model of the regional freight transportation process as an integer programming problem}

In general, ideologically and methodologically, the conducted research is in line with the egalitarian approach in the theory of welfare [11]. We represent the paradigm of cooperative decision-making in the form of an optimization problem with a set of objective functions and a number of constraints, through which the economic interests of the considered agents of the transportation process are taken into account to one degree or another.

Let us explain the general assumptions that are made in the formulation of optimization problems. $m$ loading station and $n$ unloading stations are considered. Let $a_{i}$ be the number of sending routes to be exported from the $i$ loading station $(i=1,2, \ldots, m)$. Since in the situation under consideration, the possibilities of receiving grain at each of the unloading stations are orders of magnitude higher than those volumes that are subject to removal from loading stations, we do not enter into consideration the value $b_{j}$, which is the number of routes that can be accepted by the $j$ unloading station $(j=1,2, \ldots, n)$. (Thus, formally, the situation can be considered related to the open model.)

Further, let $x_{i j}$ be the number of sending routes that can be directed from the $i$ loading station to the $j$ unloading station $(j=1,2, \ldots, n)$. As the initial set of admissible transportation plans $D$, we will consider the set of plans $\left(x_{i j}\right)$ for which the equalities are satisfied:

$$
\sum_{j=1}^{n} x_{i j}=a_{i}(i=1,2, \ldots, m)
$$


Thus, it is assumed that all grain located at the loading stations and planned for export to the unloading stations, the volume of which is equal to $\sum_{i=1}^{m} a_{i}$, should be transported to these stations.

\subsubsection{Optimization model of the transportation process with two indicators}

Let us comment on the indicators of the freight transportation process considered in this work, the values of which largely characterize the economic feasibility and quality of the organization of this process.

Let $t_{i j}$ be the time spent by the sending route in the section between the $i$ rd loading station and the $j$ th unloading station. It is correct to assume that the time $t_{i j}$ does not depend on the above values of $x_{i j}$, since these values are very insignificant in comparison with the number of all sending routes that are on the considered loop at each moment of time.

The first time indicator is the objective function of the optimization problem, which has the form:

$$
\tau=\sum_{i=1}^{m} \sum_{j=1}^{n} t_{i j} x_{i j}
$$

For each transportation plan $\left(x_{i j}\right)$, the value $\tau$ is the total time spent on the loop of all sending routes that participate in the implementation of this plan. Indicator $\tau$ expresses (calculated in days) the operating time of a part of the track infrastructure of the loop when the corresponding plan is implemented. Thus, the value of this indicator directly affects the degree of deterioration of the specified infrastructure. Acting on behalf of the Russian state, Russian Railways is an agent whose interest in the value of this indicator is twofold. On the one hand, the economic benefit of the specified agent is the result of the operation of the specified infrastructure. On the other hand, the degree of operation of the track infrastructure is directly related to the amount of expenses that are required for the corresponding depreciation. In the optimization problem arising in this way, the minimization of the index $\tau$ has another aspect that is not directly related to anyone's commercial interests. This minimization corresponds to the principles of green logistics, following which is a necessary condition for the existence of modern society.

Note that we can separately consider the integer mathematical programming problem $\tau \rightarrow$ min with constraints (2) for one linear objective function (3). In such a situation, a plan is optimal in which the sum of all time spent on the range of all routes included in the transportation of this plan does not exceed the sum of all time spent on the range of all routes included in the transportation of any other plan.

Along with the time indicator $\tau$, we will consider the cost indicator, which expresses the objective function of the form:

$$
c=\sum_{i=1}^{m} \sum_{j=1}^{n} c_{i j} x_{i j}
$$

Objective functions $\tau$ and $c$ are not literally conflicting with each other. As can be seen from the results of the computational procedures given below, for indicators $\tau$ and $c$ there is a pronounced correlation (which is natural), which, however, is not strictly monotonic.

Further, an optimization problem with some set $D$ of admissible transportation plans and two objective functions $\tau$ and $c$ is considered. Each transportation plan $\left(x_{i j}\right) \in D$ is assigned a vector, called a utility vector. An optimal transportation plan is $\left(x_{i j}^{\prime}\right) \in D$ with a utility vector $\left\{\tau^{\prime}, c^{\prime}\right\}$, for which there is no transportation plan $\left(x_{i j}^{\prime}\right) \in D$ such that the coordinates of its utility vector $\{\tau, c\}$ satisfy condition $\left(\tau \leq \tau^{\prime}\right.$ and $\left.c<c^{\prime}\right)$ or condition $\left(\tau<\tau^{\prime}\right.$ and $c \leq$ $\left.c^{\prime}\right)$. 


\subsubsection{Implementation of the optimization algorithm by virtue of the software}

Here will be given the results of a cycle of computational procedures performed in the process of solving the above optimization problem with objective functions and for the indicated five loading stations and four unloading stations (section 1.2). It is assumed (for the sake of clarity) that there are 3 routes with grain at each loading station. The system of analytical calculations Maxima (Free Ware) is used as software.

The first step of introducing constraints in the optimization problem. When choosing restrictions on the set of admissible transportation plans, we first use the territorial picture of the regional oligopolistic freight transportation market obtained in section 2.2.2 (figure 4). Since the port stations Novorossijsk, Taman' and Azov fall into the «influence area» of the loading station Albashi, and also due to the large capacity of the warehouse infrastructure of the Novorossijsk and Taman' stations, we will assume that all routes from Albashi should be directed to these two port stations. The second limitation will be formulated on the basis of the fact that the port station Tuapse falls into the « influence area» of the Tihoreckaya loading station (figure 4). Therefore, we will assume that, for example, at least two routes should be sent from this loading station to the Tuapse station. Note that so far we do not impose any restrictions (neither from above nor from below) on the number of routes that can be directed to address the port station Azov, for example.

Table 3 shows four transportation plans (out of many hundreds of thousands of plans that make up the above set of admissible plans and analyzed in the Maxima environment according to the compiled algorithm), for which the plan was improved in the sense of Pareto optimization with two objective functions $\tau$ and $c$. The optimal transportation plan contained in the last row of the table shows that not a route gets to Taman' station, and 10 routes (out of 15 routes with grain located at the five loading stations under consideration) should be directed to the port station Azov.

Table 3. Feasible transportation plans at the first step of the optimization process.

\begin{tabular}{|c|c|c|c|c|c|c|c|}
\hline \multirow[b]{2}{*}{ № } & \multirow[b]{2}{*}{ Transportation plan } & \multicolumn{4}{|c|}{$\begin{array}{c}\text { Number of routes } \\
\text { arriving at port stations }\end{array}$} & \multirow[b]{2}{*}{$\tau$} & \multirow[b]{2}{*}{$c$} \\
\hline & & $\begin{array}{l}\overrightarrow{0} \\
0 \\
0 \\
0 \\
0 \\
0 \\
z\end{array}$ & 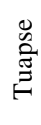 & 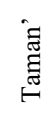 & 定 & & \\
\hline 1 & $0,0,0,3,0,0,3,0,0,0,0,3,0,2,0,1,0,0,0,3$ & 0 & 2 & 3 & 10 & 12,67 & 27767.50 \\
\hline 2 & $0,0,0,3,1,0,2,0,0,0,0,3,0,2,0,1,0,0,0,3$ & 1 & 2 & 2 & 10 & 12,50 & 27561.50 \\
\hline 3 & $0,0,0,3,2,0,1,0,0,0,0,3,0,2,0,1,0,0,0,3$ & 2 & 2 & 1 & 10 & 12,33 & 27355.50 \\
\hline 4 & $0,0,0,3,3,0,0,0,0,0,0,3,0,2,0,1,0,0,0,3$ & 3 & 2 & 0 & 10 & 12,16 & 27149.50 \\
\hline
\end{tabular}

So, at the first step of the research carried out in the particular situation under consideration, we can conclude that the above two constraints in the considered optimization problem are not enough to fully reflect the reality of the situation under consideration.

The second step of introducing constraints in the optimization problem. The reality of the situation is characterized, first of all, by objective circumstances, among which we will single out two. These circumstances are associated with the peculiarity of the geographical location of the seaports considered in this work and their export potential.

Let's start with the port of Azov, which is located at the mouth of the Don and is accessible for vessels with a draft of up to $4 \mathrm{~m}$. In winter, navigation in this area is carried out using icebreaker assistance (which implies additional costs). This port can be visited by sea vessels with a deadweight of up to 7 thousand tons. If we consider the dispatch routes, consisting of an average of 50 wagons with a carrying capacity of 64 tons each, then each such vessel is practically filled with 2 routes. When exporting grain, the freight is transported to the Black 
Sea by ships of the specified capacity, and then at the roadstead is reloaded into Panamaxtype vessels. The small capacity of the railway approaches to the port of Azov and the absence of large-capacity warehouses in it lead to the need for careful planning of the time for the delivery of goods. (Note here that the bulk of grain cargo is delivered to the port by an active competitor - road transport). Thus, the volume of cargo arriving at the port is strictly regulated and constantly monitored. Thus, for railway transport, the organization of the transportation process is of particular relevance, which makes it possible to exclude nonstandard idle time of rolling stock in anticipation of unloading.

Table 4. Feasible transportation plans at the second step of the optimization process.

\begin{tabular}{|c|c|c|c|c|c|c|c|}
\hline \multirow[b]{2}{*}{ № } & \multirow[b]{2}{*}{ Transportation plan } & \multicolumn{4}{|c|}{$\begin{array}{l}\text { The number of routes } \\
\text { that arrived at the port } \\
\text { stations }\end{array}$} & \multirow[b]{2}{*}{$\tau$} & \multirow[b]{2}{*}{$c$} \\
\hline & & $\begin{array}{l}\text { 总 } \\
: \overrightarrow{0} \\
0 \\
0 \\
0 \\
0 \\
0 \\
z\end{array}$ & $\begin{array}{l}0 \\
\stackrel{0}{0} \\
\stackrel{\Xi}{\Xi} \\
\text { F. }\end{array}$ & : & $\begin{array}{l}\overrightarrow{0} \\
\text { ¿ }\end{array}$ & & \\
\hline 1 & $0,0,3,0,0,0,3,0,0,0,0,3,0,2,0,1,0,0,3,0$ & 0 & 2 & 9 & 4 & 16.84 & 31702.00 \\
\hline$\cdots$ & $\cdots$ & $\cdots$ & $\cdots$ & $\cdots$ & $\cdots$ & $\cdots$ & $\cdots$ \\
\hline 77 & $0,0,0,3,0,0,3,0,3,0,0,0,0,2,0,1,3,0,0,0$ & 6 & 2 & 3 & 4 & 13.42 & 28480.00 \\
\hline$\cdots$ & $\cdots$ & $\cdots$ & $\cdots$ & $\cdots$ & $\cdots$ & $\cdots$ & $\cdots$ \\
\hline 91 & $0,0,0,3,2,0,1,0,1,1,0,1,1,2,0,0,3,0,0,0$ & 7 & 3 & 1 & 4 & 13.11 & 28090.50 \\
\hline 92 & $0,0,0,3,2,0,1,0,2,0,0,1,1,2,0,0,3,0,0,0$ & 8 & 2 & 1 & 4 & 13.08 & 28090.50 \\
\hline 93 & $0,0,0,3,2,0,1,0,3,0,0,0,0,2,0,1,3,0,0,0$ & 8 & 2 & 1 & 4 & 13.08 & 28068.00 \\
\hline$\cdots$ & $\cdots$ & $\cdots$ & $\cdots$ & $\cdots$ & $\cdots$ & $\cdots$ & $\cdots$ \\
\hline 97 & $0,0,0,3,3,0,0,0,0,2,0,1,1,2,0,0,2,1,0,0$ & 6 & 5 & 0 & 4 & 13.00 & 27884.50 \\
\hline 98 & $0,0,0,3,3,0,0,0,0,2,0,1,1,2,0,0,3,0,0,0$ & 7 & 4 & 0 & 4 & 12.97 & 27884.50 \\
\hline 99 & $0,0,0,3,3,0,0,0,1,1,0,1,1,2,0,0,3,0,0,0$ & 8 & 3 & 0 & 4 & 12.94 & 27884.50 \\
\hline 100 & $0,0,0,3,3,0,0,0,2,0,0,1,1,2,0,0,3,0,0,0$ & 9 & 2 & 0 & 4 & 12.91 & 27884.50 \\
\hline 101 & $0,0,0,3,3,0,0,0,3,0,0,0,0,2,0,1,3,0,0,0$ & 9 & 2 & 0 & 4 & 12.91 & 27862.00 \\
\hline
\end{tabular}

Regarding the ports of Novorossiijsk, Tuapse and Taman' located on the Black Sea coast, we note that they are ice-free ports and deep-water. Through these ports, year-round navigation is carried out and sea vessels with a draft of up to $19 \mathrm{~m}$, such as Panamax, with a deadweight of up to 80 thousand tons are accepted, which corresponds to 25 shipping routes. There are large grain terminals in the ports, which allow loading grain from the warehouse without waiting for the arrival of trains to fill the vessel. Note, in general, that the loading capacity of the deep-water ports of the Black Sea is incomparably large with the capacity of a sea vessel and allows processing large volumes of grain cargo arriving by rail or road and further exported by sea.

In accordance with the above-mentioned features of the Azov port station, in the considered optimization problem, we introduce an additional restriction to those made above, according to which exactly 4 routes should be sent to the address of this station. We proceed from the assumption that the volume of grain contained in them practically corresponds to the carrying capacity of two vessels with a deadweight of up to 7 thousand tons. Note that, as in the first step of the research, we do not yet impose any restrictions on the number of routes that can be directed to address of three deep-water port stations. 
Table 4 shows twelve transportation plans (out of 101 plans for which the plan was improved in the sense of Pareto optimization with two objective functions $\tau$ and $c$ ). From the given values one can see the relationship between the values of the considered objective functions (not having a strictly monotonic character).

The optimal transportation plan contained in the last row of table 4 shows that, as before, not a single sending route reaches Taman' station.

The third step of introducing constraints in the optimization problem. We see that if the optimization algorithm does not impose restrictions from below on the number of routes that can be directed to the port stations Novorossiijsk, Tuapse and Taman', then the Taman' station is not at all in demand. Therefore, along with the restrictions made above, we will assume that at least one route should be directed to each of the three indicated stations.

Note also that (for this, see the beginning of section 3.1), according to the algorithm for solving the optimization problem under consideration, for participants in the transportation process interested in minimizing each of the indicators and, equality is assumed in the sense that it is understood in the egalitarian approach in the theory of welfare. The above can be attributed to an operator company providing rolling stock for transportation, a carrier that owns the infrastructure (that is, Russian Railways), which has undertaken to transport goods, as well as a cargo owner.

In table 5, we give 12 transportation plans out of 80 plans, successively found by the system of analytical calculations, such that with the transition to each next plan, the indicators improve in accordance with the Pareto criterion.

Table 5. Feasible transportation plans at the second step of the optimization process.

\begin{tabular}{|c|c|c|c|c|c|c|c|}
\hline \multirow[b]{2}{*}{ № } & \multirow[b]{2}{*}{ Transportation plan } & \multicolumn{4}{|c|}{$\begin{array}{l}\text { The number of routes that } \\
\text { arrived at the port stations }\end{array}$} & \multirow[b]{2}{*}{$\tau$} & \multirow[b]{2}{*}{ 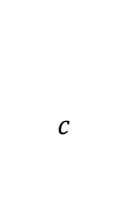 } \\
\hline & & 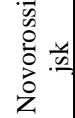 & 总 & 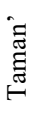 & 总 & & \\
\hline 1 & $1,0,2,0,0,0,3,0,0,0,0,3,0,2,0,1,0,0,3,0$ & 1 & 2 & 8 & 4 & 16.62 & 31521.00 \\
\hline 2 & $1,1,1,0,0,0,3,0,0,0,0,3,0,2,0,1,0,0,3,0$ & 1 & 3 & 7 & 4 & 16.43 & 31340.00 \\
\hline 25 & $2,0,0,1,0,0,3,0,0,0,0,3,0,2,1,0,3,0,0,0$ & 5 & 2 & 4 & 4 & 15.04 & 30136.00 \\
\hline 26 & $1,1,0,1,0,0,3,0,0,0,0,3,0,3,0,0,0,3,0,0$ & 1 & 7 & 3 & 4 & 14.98 & 29961.50 \\
\hline 63 & $0,0,0,3,0,0,3,0,2,0,0,1,1,2,0,0,3,0,0,0$ & 6 & 2 & 3 & 4 & 13.42 & 28502.50 \\
\hline 64 & $0,0,0,3,0,0,3,0,3,0,0,0,0,2,0,1,3,0,0,0$ & 6 & 2 & 3 & 4 & 13.42 & 28480.00 \\
\hline 75 & $0,0,0,3,2,0,1,0,0,2,0,1,0,3,0,0,3,0,0,0$ & 5 & 5 & 1 & 4 & 13.18 & 28153.50 \\
\hline 76 & $0,0,0,3,2,0,1,0,0,2,0,1,1,2,0,0,2,1,0,0$ & 5 & 5 & 1 & 4 & 13.17 & 28090.50 \\
\hline 79 & $0,0,0,3,2,0,1,0,2,0,0,1,1,2,0,0,3,0,0,0$ & 8 & 2 & 1 & 4 & 13.08 & 28090.50 \\
\hline 80 & $0,0,0,3,2,0,1,0,3,0,0,0,0,2,0,1,3,0,0,0$ & 8 & 2 & 1 & 4 & 13.08 & 28068.00 \\
\hline
\end{tabular}

For the optimal plan given in the last row of the table, the total time spent on the loop of all the routes that make up this plan turned out to be 13.08 days, and the cost of transportation was equal to 28,068 thousand rubles (taking into account that each route consists of 50 vagons). At the same time, 8, 2 and 1 routes should be sent to the port stations Novorossiijsk, Tuapse and Taman', respectively.

Summing up the general result of the performed computational procedures, we draw attention to the fact that in the proposed approach in optimizing the freight transportation process, a significant role is assigned to a mathematical experiment, which is a very effective heuristic tool for simulation. Modeling of the transportation process can be purposefully and 
flexibly accompanied by the manipulation of various kinds of restrictions imposed on the transportation of goods, based on the operational situation and expert recommendations.

\section{Conclusion}

The synthesis of ideas and the development of methods for joint use of the previous proposed approaches are becoming increasing important in modern studies of the organization of the multimodal freight transportation process along with the development existing methods for finding rational distributions of freight flows.

Techniques developed in the environment of computer mathematics systems and using the computational, analytical, graphic, animation, as well as heuristic capabilities of these software products make it possible to create mathematically substantiated and visual models of the oligopolistic freight market in the region under consideration. The orientation of the approach to the study of market mechanisms of the transportation process is expressed in the fact that when building these models in one form or another, the interests of various subjects of this process are taken into account.

In this paper, we propose a methodology for studying the organization of the process of multimodal freight transportation at the loop, which is based on a synthesis of two having the various mathematical nature developed earlier by the authors approaches to study the economic efficiency of these transportation. The results obtained make it possible, in accordance with the current operational situation, to correct the territorial picture of the transportation process and find the most rational options for using rolling stock when transporting goods to destination stations.

\section{References}

1. Aulin V, Lyashuk O, Pavlenko O, Velykodnyi D, Hrynkiv A, Lysenko S, Holub D, Vovk Y, Dzyura V and Sokol M 2019 Communications - Scientific letters of the University of Zilina 21(2) 3

2. Krajcovic M, Grznar P, Fusko M and Skokan R 2018 Communications - Scientific Letters of the University of Zilina 20(4) 16

3. Prachi A, Talari G 2018 Advances and Applications in Mathematical Sciences 18(1) 45

4. Shramenko N Y, Shramenko V O 2018 Naukovyi Visnyk Nat-sionalnoho Hirnychoho Universytetu 5(167) 136141

5. Pronello C, Camusso C and Valentina R 2017 Transportation Research Procedia 25(0) 888

6. Chislov O N, Bogachev V A, Zadorozhniy V M, Demchenko O I, Khan V V and Bogachev T V 2019 Transport problems 14(2) 77

7. Chislov O N, Zadorozhniy V M, Bogachev T V, Kravets A S, Egorova I N and Bogachev V A 2020 Smart and Green Solutions for Transport Systems 1091126

8. Kozachenko D, Skalozu V, Hermaniuk Y, Korobiova R, Gorbova A 2019 Transport Problems 14(3) 17

9. Teye C, Hensher D A 2019 ITLS Working Papers 1

10. Knoop V, Hoogendoorn S 2015 European Journal of Transport and Infrastructure Research 15(2) 226

11. Moulin H 1989 Axioms of Cooperative Decision Making (Econometric Society Monographs) (Cambridge: Cambridge University Press, New York) 